\title{
LA DIVERSIDAD DE PLANTEAMIENTOS EN LOS ESTUDIOS DE PAISAJE. REFLEXIONES EN TORNO A UNA CUESTIÓN CANDENTE
}

\section{DIVERSITY OF APPROACHES OVER LANSDSCAPE STUDIES}

\author{
David Serrano Giné y Nathanael Bennassar
}

Recibido 18/09/2009; aceptado el 24/03/2011

Resumen: El término paisaje comporta un número elevado de acepciones que, en ámbitos académicos, se traduce en una importante diversidad de planteamientos de trabajo. A menudo no resulta sencillo diferenciar estos enfoques y es fácil confundir tendencias de estudio. Bajo esta coyuntura, se ofrece una sistematización de las diferentes consideraciones que, desde el mundo académico, se tiene acerca del paisaje, fijando especial atención en lo relativo a la Geografía.

PALABRAS CLAVE: Paisaje, geografía, paisajismo, ecología del paisaje

Abstract: The voice landscape implies an elevated number of meanings that, in academic circles, are translated in a diversity of approaches. Often it is not easy to differentiate these approaches and it is easy to confuse tendencies. Under this conjuncture, a systematization of the different considerations is offered, making special attention towards Geography.

KEY WORDS: Landscape, geography, landscaping, landscape ecology

\section{INTRODUCCIÓN}

"Paisaje» es un concepto vago e impreciso, que comporta siempre un grado de ambigüedad y polivalencia, un tipo de indefinición que facilita un uso dilatado y, a menudo, confuso. Se trata, pues, de un significante con diferentes significados que, de un tiempo a esta parte, ha sido divulgado, popularizado y utilizado dilatadamente, tanto dentro como fuera de círculos académicos (Serrano, García y Paül, 2006).

En ámbitos académicos son diversas las disciplinas que toman el paisaje como objeto de estudio, ya sea de manera primordial, ya sea de manera secundaria. Filósofos, pintores, literatos, psicólogos, economistas, letrados, arquitectos, ingenieros, biólogos, ecólogos, geógrafos e historiadores, entre otros, se acercan al tratamiento académico del paisaje. Sin embargo, estos enfoques desde diferentes disciplinas no son unitarios, sino que varían entre escuelas de trabajo, centros de investigación e, incluso, profesionales. Así, se constata una heterogeneidad de intereses, que conduce a una gran diversidad de planteamientos epistemológicos y de trabajo, y que se añaden a la particular interpretación que cada profesional hace del paisaje.

Fuera de círculos académicos el paisaje se ha utilizado a menudo como pretexto. Como una especie de paraguas donde cobijar diferentes ideas o inquietudes, de carácter territorial, social, ambiental o estético, siempre en un sentido amplio y poco definido. El paisaje, por tanto, se utiliza como un subterfugio de fácil acceso, donde amparar inquietudes difíciles de cobijar bajo otras voces.

La multiplicidad de acepciones de la palabra paisaje y su uso en diferentes contextos, no facilita una estandarización de significados, propiciando un uso laxo de la palabra. Desde planteamientos estrictamente lingüisticos por paisaje se acostumbra a entender por primera y principal acepción "fisonomía del territorio», generalmente 
desde una perspectiva artística (Figura 1). Desde otros planteamientos la diversidad de consideraciones es aún superior, de tal manera que se dejan de manifiesto matices diferenciales, que pueden llegar en desembocar en posturas difícilmente compatibles (Figura 2.).

La polivalencia de significados parece encontrarse implícita en la misma palabra que, desde sus orígenes, presenta diferentes acepciones. Etimológicamente paisaje deriva del latín pagus que, al igual que país, significa "campo", "tierra». En algunas lenguas, como el francés o el catalán, esta acepción es equivalente a región y se vincula, particularmente, al mundo rural. En otras lenguas, como el español, únicamente se ha conservado el carácter administrativo del término ${ }^{1}$ (Tort, 2003). De pagus derivan todos los paisajes de las lenguas románicas: paisaje en español, paisatge en catalán, paisaxe en gallego, paisagem en portugués, paysage en francés, paesaggio en italiano, païsatge en occitano, peisai en rumano, paisaç en retorromano. En lenguas germánicas también se mantiene el origen territorial de la etimología (land), de donde se deriva landscape en inglés, Landschaft en alemán, landschap en neerlandés, landkap en afrikáner, landskap en sueco, lanskab en danés. Estas soluciones de raíz land parecen encontrarse citadas por primera vez en germánico antiguo el año 830, bajo las formas Lantscafy Lanscakt, curiosamente como traducciones del latín regio (Tress y Tress, 2001).

Sin embargo, el término paisaje no se popularizó hasta el siglo XVIII, cuando distintas lenguas tomaron esta voz, fundamentalmente para describir el género pictórico creado por Patinir y, más tarde, difundido por Durero. En este sentido, paisaje envía la acepción de "vista interpretada estéticamente». A partir del siglo XIX paisaje pasa a entenderse también como "configuración territorial" o "expresión ecológica de sociedades», hecho que facilita su difusión en disciplinas de carácter espacial, como la Geografía, que canaliza en él buena parte de su cometido (Bolòs, 1992).

A propósito de esta dualidad de concepciones, se ha señalado que el paisaje, en las lenguas romances, comporta connotaciones de cariz estético bastante alejadas de las que se denotaban en latín o en antiguo germánico. Autores como Antonio Higueras (1999) advierten que el significado tradicionalmente atribuido desde la Geografía se encuentra en traducciones hechas en el siglo XIX del alemán Landschaft que, en esta lengua, tanto se refieren a la percepción interiorizada de la realidad como a una porción de territorio considerada holísticamente.

\section{LA CONSIDERACIÓN DEL PAISAJE EN GEOGRAFÍA}

La consideración del paisaje, como campo de trabajo de la Geografía, acostumbra a explicarse a partir de un marco epistemológico que se configura a mediados del siglo XIX. En esta fecha el cometido de los científicos naturalistas supera las actividades académicas tradicionales, centradas en recoger, describir y clasificar los distintos elementos de la naturaleza, y comienza a fijar interés en los conjuntos que se derivan y la forma en que se estable- cen interrelaciones. De esta guisa, diferentes autores estudian, aún de manera prudente, los vínculos y configuraciones de la naturaleza.

En la era común esta concepción integrada de la naturaleza se manifiesta en loables precursores, como fray Bartolomé de las Casas o Simón de Rojas Clemente y Rubio. Aun y así, la tradición fija Alexander von Humboldt como el primer autor de renombre que repara en ello de manera evidente, dejando de manifiesto sus conocimientos en la obra Cosmos, publicada entre 1834 y 1860 . Ernest Haeckel, el año 1866, también advierte esta coyuntura, y la evidencia con la creación del término ecología ("la ciencia de las relaciones de los seres vivos entre ellos y su entorno»). La tradición también apunta un vínculo entre Humboldt y la Geografía, y entre Haeckel y la Biología.

La aportación de Humboldt facilitó la creación de un espacio de trabajo propicio al estudio riguroso de la superficie terrestre, alrededor del cual diferentes autores inician la elaboración de teorias propias. Según Gustav Fochler-Hauke (1953), Siegfried Passarge y Carl Sauer serian pioneros en considerar el paisaje como tema central de la Geografía, si bien fuera Otto Schlüter el primero que definió la Geografía como "ciencia del paisaje». En cualquier caso, conviene notar el carácter de totalidad con el que se concebía el paisaje en esta época:

"las ideas filosóficas de la totalidad de los fenómenos han ganado particularmente influencia sobre la Geografía, fomentando el nacimiento del concepto que una Corología con leyes propias sólo es realizable, si el "ser" del paisaje es percibido como una estructura integra de relaciones y definida en forma particularn (FochlerHauke, 1953: 8).

Julio Muñoz (1989) ha estudiado la evolución y la conceptualización de la noción de paisaje en el ámbito de la Geografía, señalando que el tratamiento académico del paisaje, durante la primera década del siglo XX, se construye a partir de las aportaciones de Passarge, Carl Sauer y Jean Brunhes. Los tres autores conciben el paisaje como una configuración, resultante de la articulación de los elementos de la superficie terrestre. Talmente, estos autores proponen el estudio desde la perspectiva del holismo, en coherencia con dicho carácter de totalidad. La completitud del paisaje, con todo, evolucionará y se matizará a medida que se profundice su tratamiento, y según la concepción que desarrollen autores y escuelas de trabajo.

A mediados de siglo XX comienzan a distinguirse dos grandes enfoques sobre la materia que, lejos de definirse, a menudo incardinan. Arturo García y Julio Muñoz (2002) indican una tendencia "historicista», preocupada por la diferenciación e individualización de la superficie terrestre, bien patente en la obra de Vidal de la Blache, y una tendencia "ecológica», interesada por las relaciones entre el ser humano y la naturaleza, bien representada por Carl Sauer. Ambas posiciones se encuentran con frecuencia y se confunden con una concepción únicamente fisonómica del paisaje; el movimiento naturalista, que aún perduraba en muchos ambientes, ayudó aún más a la confusión de posturas. De esta manera, la corriente histo-

1 Considérense, sin embargo, expresiones tan castizas como "por estos pagos», y similares. 
ricista seguía manteniendo los lazos sensitivos que promulgaba Humboldt, mientras que la escuela ecológica ya los había perdido. Aparte, se le añadía una de las concepciones de paisaje más difundida, que entendía el paisaje únicamente como expresión fisonómica:

«El paisaje, elaborado como un concepto geográfico, cambiaba el acento pero no transformaba los fundamentos conceptuales del espacio geográfico. El concepto de paisaje permitía destacar los componentes visuales del espacio, la combinatoria específica que, de modo aparente, distinguía, en cada caso, la singularidad geográfican (Ortega, 2000:349).

De todo ello se deriva una definición de paisaje incompleta e individual, ya que cada autor agrupaba conocimientos diferentes bajo un mismo concepto que, por ser vago, también era válido. La dispersión de enfoques y contenidos, y su utilización partidista, provoca que en estos momentos el paisaje aparezca como un objeto de estudio poco riguroso, ambiguo e intuitivo; acientífico según el pensamiento neopositivista de la época. Discordias individuales aparte, las contradicciones epistemológicas, teóricas y aplicadas son constantes en este periodo (Luis, 1980).

De manera simultánea, la pervivencia de planteamientos estructuralistas, el desarrollo de la ecología de Haeckel y la aparición de la Teoría General de Sistemas, difunden un nuevo talante al cometido académico del paisaje. En esta ocasión la canalización se realiza a partir de planteamientos espaciotemporales, holísticos y con una clara noción escalar y taxonómica (Frolova, 2001). En torno a esta concepción son dos las escuelas que se crean: la llamada "Ciencia del geosistema", preocupada por el estudio sistemático, cuantificado e interrelacionado de fenómenos de la superficie terrestre y de la atmósfera, y el "Reconocimiento de territorios» centrado en caracterizaciones territoriales a pequeña escala. Ninguna de estas dos posturas ha pervivido inalterada hasta la actualidad, si bien es cierto que algunos de sus rasgos más llamativos han sido tomados por otras escuelas. La más importante de éstas, posiblemente, sea la llamada "escuela de Tolosa», encabezada por Georges Bertrand.

Como respuesta a las tendencias teoréticocuantitativas desde donde se construyen algunos de estos planteamientos, durante la segunda mitad de siglo XX aparecen propuestas que propugnan valores de tipo cualitativo, afectivo y personal en el tratamiento académico del paisaje. En Geografía esto se materializa en el nacimiento de la Geografía humanista y la Geografía de la percepción y el comportamiento, profundamente relacionadas con la Psicología y la Sociología. Estas tendencias fijan interés en la percepción y la valoración del paisaje, y entroncan con posturas de carácter estético y filosófico.

En épocas recientes se constata la aparición de tendencias basadas en el uso de la informática. Estas perspectivas consideran el paisaje de manera sistematizada, y han sido favorecidas por la popularización de diferentes software, la difusión de imágenes de satélite, el uso de sistemas de información geográfica y el perfeccionamiento de metodologías cuantitativas. Buena prueba de ello es la aparición de índices y métricas del paisaje, así como la divulgación de todo aquello más o menos relacionado con la modernamente llamada ecología del paisaje. A su vez, esta tendencia ha dado pie a una reanudación de otros enfoques más laxos y personalizados, de carácter más subjetivo y centrados en la esfera del individuo, como se pone de manifiesto, por ejemplo, en la recopilación editada recientemente por Joan Nogué (2007).

\section{EL PAISAJE Y SU CONSIDERACIÓN ACADÉMICA}

En el ámbito académico actual, la dispersión de planteamientos en el tratamiento del paisaje se manifiesta de manera recurrente. Luis Cáncer (1994) ha demostrado que el paisaje es objeto de estudio de diversas disciplinas si bien, al abordarse desde perspectivas diferentes, cada cual centra su atención en alguna de las muchas acepciones que presenta el término. Debido a la multitud de campos de dedicación y la diversidad de ópticas e intereses académicos, no resulta fácil recapitular y diferenciar entre posiciones. Esta dificultad aumenta si se contempla la evolución propia de cada escuela de trabajo, sus distintos intereses o la aparición de disidencias internas, así como la existencia de planteamientos puntuales o de conveniencia.

Con todo, en lo que respecta a la manera de aproximarse, es posible distinguir entre planteamientos que toman el paisaje como algo interno propio del sujeto y exclusivo de la asimilación humana, y planteamientos que fijan atención en el paisaje como algo externo al ser humano $y$, por lo tanto, fácil de objetivar; no faltan, evidentemente, tendencias integradoras que contemplen ambos enfoques en diferente grado. Florencio Zoido y Franco Posocco (1998) sugieren diferenciar tres grandes perspectivas: una primera, ocupada en la dimensión territorial del paisaje y en su carácter objetivo; una segunda, preocupada por la intervención en el paisaje a partir de consideraciones principalmente visuales y una última, centrada en fijar énfasis en los aspectos subjetivos del paisaje percibidos y asimilados por el individuo.

Según la metodología de trabajo, es interesante referirse a la distinción de José Ramón Díaz de Terán (1988), que distingue una línea de trabajo analítica y otra sistémica. La primera considera el paisaje como la superposición de una serie de elementos que permiten la zonificación del territorio, aunque no comporta, necesariamente, la integración de éstos. La segunda se constituye sobre unidades homogéneas, e implica cierto grado de subjetividad, relacionado con la escala de trabajo, los criterios de delimitación utilizados y el propósito del estudio; sin embargo, comporta una buena aprehensión del territorio, explica las diferencias sectoriales y ofrece una buena visión de conjunto.

Ninguna de estas líneas de trabajo se identifica completamente con disciplinas académicas puesto que, a menudo, profesionales de un mismo campo se sobreponen o divergen en función de distintos intereses, que no tienen porque depender del talante general de cada disciplina.

En un ejercicio de síntesis sistematizamos los enfoques que el paisaje, como objeto de estudio, es capaz de sugerir. La propuesta 
alcanza los distintos planteamientos existentes, los caracteriza y los sitúa en interrelación. Debido a las muchas facetas del término, ha sido necesario tratar con rigor cada enfoque propuesto, cosa que entra en contradicción con la permeabilidad y la superposición actual. Nuestra intención no es crear más disparidad, sino simplemente definir para poder distinguir, comprender y situar correctamente diferentes líneas de trabajo:

- En ámbitos centrados en el pensamiento y la mente humana, el paisaje se concibe como una creación subjetiva, sólo inteligible a partir de filtros culturales y sociales. Este razonamiento puede canalizarse a través de la ética y las relaciones individuo-medio, y a través de la teoría de la belleza. Según Alain Roger (2000:20) «la naturaleza es indeterminada y sólo el arte la determina: un territorio sólo deviene paisaje bajo la condición de un paisaje, y eso es así siguiendo las dos modalidades de artialización²: la móvil (in visu) y la adherente (in situ)n. El autor explica que la primera se refiere a la elaboración de modelos autónomos (pictóricos, escultóricos, fotográficos, etc.), que constituyen un dispositivo suplementario -el de la mirada- al propio territorio. La segunda, en cambio, atiende propiamente la transformación física de este territorio mediante un planteamiento artístico. Analizando el arte doctrinalmente se alcanza la estética; analizando el paisaje introspectivamente, a la psicología ambiental.

- En ámbitos de mayor sensibilidad (especialmente en pintura pero también en literatura) el paisaje se entiende como una interpretación artística procesada estéticamente. En Japón y en China, bajo el amparo de las dinastías T'ang, Song y Yuan (siglos VII-XIV), una serie de artistas recrean paisajes con intenciones únicamente estéticas, a partir de invenciones como el horizonte o la representación de la lluvia; muestra de esta sensibilidad es la creación de espacios en blanco para invitar al espectador a entrar en la obra. En Occidente unos valores paisajisticos parecidos empiezan a representarse en el Quattrocento italiano como telones de fondos o creaciones lineales en primer plano. Desde Giotto el paisaje comienza a tomar carácter autónomo en pintura: La tempestad de Giorgione o El nacimiento de Adonis de Tiziano se sitúan en esta etapa inicial. La aparición de técnicas como la perspectiva, la profundidad o las líneas caracterizan esta época, y manifiestan una mayor voluntad de interacción entre el lienzo y el espectador. Con Santa María Egípcia o María Magdalena, Tintoretto apunta hacia el paisaje como método de expresión con creciente protagonismo dentro de la representación. El paisajismo pictórico stricto sensu se da con la escuela flamenca, mucho más refinada y habituada a las dobles perspectivas, el cromatismo armónico y la inclusión de elementos antrópicos. Artistas como Durero o Rubens hacen del paisaje motivo principal de representación, tradición que continuará con románticos e impresionistas.

- En planteamientos introspectivos el paisaje pasa por ser una construcción individual, realizada desde la mente de cada observador y susceptible de ser modificada, por factores internos o externos al sujeto. Desde este razonamiento presentan un interés parejo los estudios de percepción y los de valoración y asimilación del paisaje. Conviene decir que los trabajos de este talante pueden ser usados con finalidades aplicadas e, incluso, como escenarios de intervención.

- La dimensión propositiva del paisaje viene de la mano del paisajismo y de planteamientos afines, que fijan especial atención en la intervención territorial a partir del conocimiento del medio natural y social implicado. En estos planteamientos prevalece siempre una clara intención aplicada.

- A caballo entre la intervención y la gestión ambiental, aparecen trabajos centrados en establecer corredores naturales y conexiones biológicas -mayormente en beneficio de la fauna- que toman el paisaje como una matriz funcional sobre la cual diseñar actuaciones. Estos planteamientos tienen un cariz netamente funcional, motivo por el cual centran su interés en el territorio.

- Entre aquellas posiciones de carácter marcadamente espacial, García y Muñoz (2002) diferencian tres grandes maneras de acercarse al paisaje: vía sumativa, vía ecológica y vía sistémica. En la primera, se parte de premisas historicistas realizando inventarios y catalogaciones tipo "cómoda", excesivamente analíticos, que no trascienden de la recopilación y el tratamiento individualizado de diferente información. En la segunda, partiendo también de metodologías historicistas, se fija atención en el binomio naturaleza-ser humano considerando la adaptación del ser humano a su medio y las fisonomías resultantes de tal relación. En la tercera, por contra, se propone un tratamiento complejo de las interrelaciones entre elementos de carácter natural y de carácter cultural, focalizando tanto en los elementos per se como en el conjunto de relaciones multidireccionales que unen y dotan el conjunto de identidad; esta tendencia se basa en conceptos de dinámica y funcionalidad, motivo por el cual puede ser utilizado en estudios de carácter aplicado. Según estos mismos autores, es posible distinguir tres escuelas de trabajo: la Ciencia del geosistema, el Reconocimiento de territorios y los Estudios integrados.

La diversidad existente, como oportunamente se ha anunciado, es más que notable. Esta heterogeneidad no sólo se contempla de manera cuantitativa, sino también cualitativa; los distintos planteamientos de trabajo a veces permeabilizan entre ellos, a veces se contraponen $y$, frecuentemente, se combinan de manera dilatada (Figura 3).

2 En palabras de Roger (2000:18), la artialización se puede definir como una operación artística que comporta una intervención sobre el objeto natural, es decir, la transformación de la naturaleza en paisaje. 


\section{A MODO DE CONCLUSIÓN}

La palabra paisaje ofrece un elevado número de acepciones y una notable diversidad de connotaciones. Esta heterogeneidad tiene su origen en ámbitos académicos y se manifiesta en estos mismos entornos, pero también en otros más populares. De un tiempo a esta parte, esta voz se ha generalizado y se ha difundido eficazmente entre distintos estratos sociales, hecho que ha supuesto más complejidad, ya que tanto sociedad como mundo académico interactúan cada vez con mayor frecuencia. En muchas sociedades el término paisaje se ha vulgarizado notablemente, usándose indistintamente en anuncios publicitarios, noticiarios, conversaciones cotidianas y discursos académicos. Gabriel Rougérie y Nicolas Beroutchachvili (1991) escriben que, en la Francia de los noventa, la popularización del paisaje era tan elevada que tanto era asumida por comerciantes como por movimientos ecologistas y políticos.

Actualmente, en nuestra sociedad, se ha difundido tanto el término que cualquier vaguedad puede ser encubierta por el "paisaje». En numerosas ocasiones la cultura de la imagen y el diseño se han canalizado a través de este término, hecho que ha aumentado su difusión. Su popularización ha conducido a su banalización y uso indiscriminado, motivado más por modas pasajeras que por precisión léxica. Esta hipertrofia del paisaje, en sus múltiples acepciones parciales, reduccionistas o que fijan atención en aspectos dominantes, ha redundado en numerosas ocasiones en una descalificación del término, usándose como un subterfugio con el cual expresar cualquier concepto de manera laxa y, por lo tanto, poco comprometida. Georges Bertrand (1968:249) reflexionaba de manera parecido hace cerca de cuarenta años: "«Paysage» est un terme désuet et imprécis, donc comode, que chacun utilise à sa guise, le plus souvent en y adjoignant un qualificatif de restriction qui en altère le sensı. Podría pensarse que esta dispersión de significados y contenidos parece inherente al paisaje.

Si se considera la evolución del tratamiento académico del paisaje, al menos en el caso de la Geografía, se aprecian las diferentes corrientes epistemológicas desarrolladas de un tiempo a esta parte. Cada una de estas corrientes ha matizado la consideración del paisaje como objeto de estudio, enriqueciéndolo y ampliándolo. El paisaje, por otra parte, ha sido también tomado a conveniencia por diferentes profesionales de diferentes disciplinas, hecho que ha derivado en un incremento de su alcance temático. De ello resulta la aparición de un único término lingüístico con multitud de acepciones complementarias y contradictorias entre sí.

La diversidad de concepciones es harto elevada y, en consecuencia, las metodologías de trabajo también lo son ${ }^{3}$. Si bien es cierto que la variedad de metodologías se justifica por sí misma si se atiende a la diversidad de cada posición, no puede justificarse la contradicción existente, incluso dentro de posiciones académicas parecidas. Por otra parte, se observan ciertos planteamientos que intentan legitimarse como propietarios intelectuales del paisaje.
Ambas realidades dificultan el establecimiento de puntos de encuentro, hecho que se manifiesta, por ejemplo, en la dificultad por establecer un vocabulario común.

Ante el pretendido holismo de ciertos planteamientos, el intento por aumentar posiciones globales se incrementa, alcanzando campos temáticos cada vez más amplios $y$, por lo tanto, de interés para otros colectivos. Este es el caso de los estudios retrospectivos, o de reconstrucción del paisaje, las valoraciones económicas, las evaluaciones de impacto ambiental o los trabajos de carácter aplicado. Sin embargo, el incremento de intereses muchas veces se ha traducido en un excepcionalismo que, inversamente a las causas que lo originaron, tiende a campos de trabajo cada vez más concretos. De manera paralela, se manifiestan líneas de estudio que intentan explicar el paisaje con la especialización del conocimiento y, a menudo, con el uso de bases estadísticas; a su vez eso ha permitido que, recientemente, planteamientos de tipo fisonómico y perceptivo tomen interés. Esta alternancia sigue sin saber conciliar la diversidad de planteamientos que se albergan bajo el paisaje, por el que es de prever que en breve se suceda una nueva tendencia academicista, digamos, compensatoria.

A pesar de todo lo que hemos anunciado, paradójicamente, se nota una clara concepción del carácter global e integrador del paisaje, y pese a admitirse la plasticidad de su uso, son muy frecuentes los planteamientos de carácter excluyente; es muy posible que esta conducta encuentre su razón de ser en una intención legitimadora. En efecto, nadie parece discutir la pluridisciplinariedad y la interdisciplinariedad en el estudio del paisaje, si bien son pocas las posiciones que realmente adoptan este talante. Vuelve a producirse redundancia cuando muchos de estos planteamientos comulguen con otros, al tiempo que discriminan deliberadamente terceros enfoques. La justificación de todo ello, tristemente, a menudo yace en pareceres personales y opiniones volubles. La variedad de ejercicios es positiva y la permeabilidad entre perspectivas es beneficiosa, pero un grado elevado de dispersión no puede ser en absoluto útil, y aún menos cuando se realiza de manera excluyente. Es evidente que este hecho redundará de manera negativa en el estudio académico del paisaje, y también en el redactado de su corpus teórico y en la práctica cotidiana que se haga.

\section{AGRADECIMIENTOS}

Durante el redactado de este artículo se ha contado con el apoyo institucional del Servei de Paisatge de la Universidad de Barcelona.

\section{REFERENCIAS BIBLIOGRÁFICAS}

BERTRAND, G: «Paysage et géographie physique globale. Esquisse methodologiquen Revue Géographique des Pyrenées et du Sud-Ouest, 39, 1968 p. 249-272.

BOLÒS, M.: Manual de ciencia del paisaje. Barcelona, Masson, 1992. 
CÁNCER, L.: «Aproximación crítica a las teorias más representativas de la Ciencia del Paisaje» Geographicalia, 31,1994, p. 17-30.

Díaz De Terán, J. R.: «Tipos y metodologias de cartografias geoambientales o neocientificas" en AYALA, F.J.; JORDÀ, J: Geología ambiental. Madrid, IGME, 1988.

FOCHLER-HAUKE, G.: Corología geográfica: el paisaje como objeto de la geografía regional. Tucumán, Universidad Nacional de Tucumán, 1953.

Frolova, M.: "Los orígenes de la ciencia del paisaje en la geografía rusa" Scripta Nova, 102, vol. V, 2001. Disponible en: <http://www.ub.es/geocrit/sn-102.htm>.

GARCÍA ROMERO, A.; MUÑOZ JIMÉNEZ, J.: El paisaje en el ámbito de la Geografía. México D.F., UNAM-Instituto de Geografía, 2002.

HIGUERAS, A: «Introducción al análisis geográfico regional. Reflexiones acerca del paisaje» Espacio, tiempo y forma, 12, Serie VI, 1999, p. 83-98.

LUIS, A.: «El geógrafo español ¿aprendiz de brujo? Algunos problemas de la geografia del paisajen Geocrítica, 25,1980.

MUÑOZ JIMÉNEZ, J.: «Paisaje y Geografía» Arbor, 518-519,1989, p. 219234.
NOGUÉ, J.: La construcción social del paisaje. Madrid, Biblioteca Nueva, 2007.

ORTEGA, J.: Los horizontes de la Geografía. Barcelona, Ariel, 2000.

ROGER, A.: Breu tractat del paisatge. Barcelona, La Campana, 2000.

ROUGERIE, G.; BEROUTCHACHVILI, N.: Géosystèmes et paysages. Bilan et methodes. Paris, Armand Colin, 1991.

SERRANO GINÉ, D.; GARCÍA ROMERO, A.; PAÜL CARRIL, V.: «El paisaje: entre la convergencia y la dispersión" Ciencia y desarrollo, 59, 2006, p. 58-64.

TORT, J.: "Obra pública i paisatge a Catalunya» en TARRAGÓ, S: (ed.): Obres públiques a Catalunya. Passat, present i futur. Barcelona, Real Academia de Ingenieria, 2003, p. 393-418.

TRESS, B.; TRESS, G: "Capitalising on multiplicity: a transdisciplinary Systems approach to landscape research" Landscape and urban planning, 57, 2001, p. 143-157.

ZOIDO, F.; POSOCCO, F.: «Política de paisaje: protección, ordenación y gestión» en ARIAS ABELLÁN, J; FOURNEAU, F. (ed.): El paisaje mediterráneo. Le paisaje méditerranéen. II paesaggio mediterraneo. Granada, Universidad de Granada y Junta de Andalucía, 2002, p. 21-35.

\section{CUADROS Y FIGURAS}

FIGURA 1: Definiciones de paisaje en distintas lenguas indoeuropeas.

- Paisaje (español): Extensión de terreno que se ve desde un sitio // Extensión de terreno considerada en su aspecto artístico // Pintura o dibujo que representa cierta extensión de terreno. (Diccionario de la Lengua Española)

- Paisatge (catalán): Aspecte, vista d'un paratge natural // Pintura d'un paisatge, d'un lloc natural (Diccionari General de la Llengua Catalana)

- Paysage (francés): Partie d'un pays que la nature présente à un observateur // Tableau représentant la nature, oủ les figures (d'hommes ou animaux) et les constructions ("fabriques") ne sont que des accessoires // Aspect général. (Le Robert. Dictionnaire de la Langue Française)

- Paisagem (portugués): Extensão de território que se abrangue num só lance de vista // Gênero de pintura ou de literatura cujo fim é a representação ou a descrição de cenas campestres // Quadro que representa essa cena. (Dicionário Universal da Língua Portuguesa)

- Paesaggio (italiano): Aspetto di un luogo, di un territorio quando lo si abraccia con lo sguardo // Particolare conformazione di un territorio resultante dagli aspetti fisici, biologici e antropici // dipinto, fotografia, che ha per soggetto vedute della realità naturale, spec. composte. (Grande dizionario italiano dell'uso)

- Landscape (inglés): A large area of countryside, esp. in relation to its appearance // A landscape is also a view or picture of the countryside. (Cambridge International Dictionary of English)

- Landschaft (alemán): Ein Teil der Oberfläche der Erde (mit Vegetation oder Häusern), so wie der Betrachter ihn sieht. (Langenscheidts Gro wörterbuch) 
Figura 2. Definiciones de paisaje propuestas por distintos autores

- Entienden [Díaz Pineda et al.] por paisaje la parte fácilmente perceptible de un sistema de relaciones subyacente, el conocimiento del cual explicaría la copresencia y la coherencia de los elementos percibidos, pero que no es fácilmente accesible a la observación directa en su totalidad. Es posible distinguir entre un fenosistema, conjunto de componentes perceptibles en forma de panorama, escena o "paisaje" y un criptosistema o complemento de más difícil observación, que proporciona la explicación que falta para la comprensión del geosistema. (González Bernáldez, 1981)

- Una porción de espacio geográfico concreto que se ajusta al modelo geosistema. (Bolòs, 1981)

- El paisaje se concibe como un sistema territorial compuesto de componentes naturales, y también de complejos de diverso rango taxonómico. (Mateo, 1984)

- Landscape is a complex of relationship systems, toguether forming (also by virtue of its physiognomy) a recognizable part of the earth's surface, and is formed and maintained by the mutual action of abiotic and biotic forces as well as human action. (Zonneveld, 1995)

- La forma que adoptan los hechos geográficos, tanto físicos como humanos, sobre la superficie de la tierra; igualmente, las representaciones que de ellos tenemos, los significados que les otorgamos y los valores que les concedemos, de manera personal o colectiva. (Gómez Mendoza, 1999)

- El concepto paisaje se asocia a una imagen visual formada por un conjunto de elementos relacionados. (García y Gutiérrez, 2000)

- Paisatge pren una part del significat d'ecosistema -una àrea lligada a un conjunt de condicions ambientals especifiques, $i$ caracteritzada per una coberta del sól diferent, o una barreja de cobertes del sòl-, però inclou de manera específica la presència de persones. (Labaree, 2000)

- Porción de espacio concerniente a la escala de las actividades humanas. Viene definido por su heterogeneidad espacial y temporal, por las actividades humanas que en él se desarrollan y por su ambiente. (Burel y Baudry, 2002)

Figura 3: Perspectivas que toman el paisaje como objeto de estudio

\begin{tabular}{|c|c|c|c|}
\hline $\begin{array}{l}\text { Consideración respecto el } \\
\text { individuo }\end{array}$ & \multicolumn{2}{|l|}{ cometido } & metodología \\
\hline \multirow{3}{*}{ consideración interna } & \multicolumn{2}{|c|}{$\begin{array}{l}\text { Actividad intelectual canalizada por la ética, las relaciones individuo-medio y la } \\
\text { teoría de la belleza }\end{array}$} & \multirow{6}{*}{ analítica } \\
\hline & \multicolumn{2}{|c|}{$\begin{array}{l}\text { Construcción individual, susceptible de ser modificada por factores internos o } \\
\text { externos al sujeto }\end{array}$} & \\
\hline & \multicolumn{2}{|c|}{ Interpretación artística procesada estéticamente } & \\
\hline \multirow{5}{*}{ consideración externa } & \multicolumn{2}{|c|}{ Actividad propositiva con objetivos sociales } & \\
\hline & \multicolumn{2}{|c|}{ Actividad propositiva con objetivos ambientales } & \\
\hline & \multirow{3}{*}{ Actividad esencialmente territorial } & Via sumativa & \\
\hline & & Vía ecológica & \multirow{2}{*}{ sistémica } \\
\hline & & Vía sistémica & \\
\hline
\end{tabular}


